\title{
Robust Stability of Fractional-Order Linear Time-Invariant Systems: Parametric versus Unstructured Uncertainty Models
}

\author{
Radek Matušů (D), ${ }^{1}$ Bilal Şenol, ${ }^{2}$ and Libor Pekař (iD) ${ }^{1}$ \\ ${ }^{1}$ Centre for Security, Information and Advanced Technologies (CEBIA-Tech), Faculty of Applied Informatics, Tomas Bata University \\ in Zlín, Nám. T. G. Masaryka 5555, 76001 Zlín, Czech Republic \\ ${ }^{2}$ Department of Computer Engineering, Faculty of Engineering, Inonu University, 44280 Malatya, Turkey
}

Correspondence should be addressed to Radek Matušů; rmatusu@fai.utb.cz

Received 14 March 2018; Revised 18 June 2018; Accepted 3 July 2018; Published 23 August 2018

Academic Editor: Ahmed Elwakil

Copyright (C) 2018 Radek Matušů et al. This is an open access article distributed under the Creative Commons Attribution License, which permits unrestricted use, distribution, and reproduction in any medium, provided the original work is properly cited.

\begin{abstract}
The main aim of this paper is to present and compare three approaches to uncertainty modeling and robust stability analysis for fractional-order (FO) linear time-invariant (LTI) single-input single-output (SISO) uncertain systems. The investigated objects are described either via FO models with parametric uncertainty, by means of FO unstructured multiplicative uncertainty models, or through FO unstructured additive uncertainty models, while the unstructured models are constructed on the basis of appropriate selection of a nominal plant and a weight function. Robust stability investigation for systems with parametric uncertainty uses the combination of plotting the value sets and application of the zero exclusion condition. For the case of systems with unstructured uncertainty, the graphical interpretation of the utilized robust stability test is based mainly on the envelopes of the Nyquist diagrams. The theoretical foundations are followed by two extensive, illustrative examples where the plant models are created; the robust stability of feedback control loops is analyzed, and obtained results are discussed.
\end{abstract}

\section{Introduction}

The impact of FO calculus ([1-5]) on real-life applications has been rapidly growing lately. It has already significantly influenced areas such as robotics $[6,7]$, signal processing [8], electrical circuits $[9,10]$ and fractance devices [11], bioengineering [12], viscoelasticity [13], and chaos theory [14]. The field of control theory is no exception to this trend. Control researchers exploit benefits of differentiation and integration under an arbitrary real or even complex number, and thus, many related scientific control-oriented works have appeared recently [15-23].

Robust control represents an efficient, attractive, and widely studied branch of control theory with direct influence on real practical applications. The principal idea is that a controller must guarantee the preservation of some property of a control loop (typically stability and performance) for all possible members from the assumed family of controlled plants defined by some uncertain model (i.e., not only for one fixed plant as in the "classical" control methods). Typically, there are two main ways of uncertainty modeling and description for SISO systems in the literature, namely, parametric [24-28] and unstructured [29-34] approach. Incorporating the uncertainty into the multipleinput multiple-output (MIMO) models is based mainly on so-called structured uncertainty and linear fractional transformations [35].

An immense amount of works, devoted to the robustness of integer-order (IO) LTI systems, has been published during the last decades. Recently, a number of authors have already tried to solve the robustness of FO LTI systems, especially under parametric uncertainty [36-50]. The particularized bibliographic research on advances in robust stability analysis of FO LTI systems with parametric uncertainty, starting from the pioneering contribution [51], can be found within the introduction of the paper [48]. However, there is still not many works focused on the robustness of FO LTI systems with unstructured uncertainty [52-54].

The paper is focused on three approaches to modeling of uncertainty and robust stability analysis for uncertain FO LTI SISO systems. More specifically, the plants are supposed to be described either by means of FO models with 
parametric uncertainty, through FO models with unstructured multiplicative uncertainty, or via FO models with unstructured additive uncertainty. Furthermore, the work presents also the possible construction of unstructured (multiplicative or additive) uncertainty models (choice of a nominal system and a suitable weight function) for plants originally considered to be affected by parametric uncertainty. From the robust stability viewpoint, the systems with parametric uncertainty are analyzed with the assistance of the value set concept in combination with the zero exclusion condition and the systems with unstructured uncertainty are graphically investigated primarily via plotting the envelopes of the Nyquist diagrams. The practical tests with a discussion of the obtained results and potential discrepancies are included in two extensive, illustrative examples.

The principal advantage of the applied graphical robust stability analysis under parametric uncertainty is its universality, that is, the technique is applicable to various uncertainty structures which suffer from a lack of alternative methods. It works even for extremely complicated uncertainty structures as well as for time-delay systems, and above all, it works not only for IO LTI systems but also for FO LTI systems of noncommensurate orders [48]. Relatively weak restrictions include the invariant degree of polynomials in the family, pathwise-connected uncertainty bounding set, and continuous coefficient functions. Then, regardless of the complexity of the uncertainty structure, the robust stability is always tested with the necessary and sufficient condition, despite some other methods that can lead to sufficient condition results only. On the other hand, a long computational time of the sampled value sets for a high number of uncertain parameters and indeterminate range of suitable frequencies for visualization represent the main disadvantages of the approach.

The robust stability of FO LTI systems with unstructured uncertainty, investigated in this paper mainly using the envelopes of the Nyquist diagrams, maintains the advantage of the necessary and sufficient condition. This holds true for both studied types of unstructured uncertainty, that is, multiplicative and additive uncertainties. However, some level of conservatism can be introduced before the robust stability test itself, during the creation of an unstructured uncertainty model. The examples in this paper discuss such conservatism caused by the replacement of the "true" plant with parametric uncertainty by an unstructured multiplicative uncertainty model. On the other hand, the unstructured uncertainty models are appropriate if unmodelled dynamics or nonlinearities are presented, and moreover, they are preferential for $H_{\infty}$-based control design methods. The multiplicative uncertainty is usually reported to be more frequently used because their numerical value is more informative when compared with the additive uncertainty [29].

The used methods may find their application in any engineering field (see the examples in the first paragraph of this section), where a control system (or typically a controlled plant) can be described by using one of the three uncertain FO LTI models that are studied in this paper and where the robust stability of the closed loop needs to be analyzed.
The paper is organized as follows. In Section 2, the basics of robust stability analysis for (FO) LTI systems with parametric uncertainty are provided. Section 3 then presents a possible description and robust stability investigation for (FO) LTI systems with unstructured multiplicative uncertainty. The analogical methods, but applicable to (FO) LTI systems with unstructured additive uncertainty, are described in Section 4. Next, two simulation examples with comparisons of various approaches are shown in Section 5. And finally, Section 6 offers some concluding remarks.

A preliminary version of this paper was presented at the IEEE Multi-Conference on Systems and Control 2016 [55].

\section{Robust Stability Analysis under Parametric Uncertainty}

The (robust) stability of the (family of) closed-loop system(s) will be tested via (robust) stability of (family of) its closedloop characteristic polynomial(s).

The continuous-time FO uncertain polynomial is assumed in the form:

$$
\begin{aligned}
p(s, \mathbf{q}) & =\rho_{n}(\mathbf{q}) s^{\alpha_{n}}+\rho_{n-1}(\mathbf{q}) s^{\alpha_{n-1}}+\cdots+\rho_{1}(\mathbf{q}) s^{\alpha_{1}}+\rho_{0}(\mathbf{q}) s^{\alpha_{0}} \\
& =\sum_{i=0}^{n} \rho_{i}(\mathbf{q}) s^{\alpha_{i}}
\end{aligned}
$$

where $\mathbf{q}$ is the vector of uncertainty, $\alpha^{n}>\cdots>\alpha^{0}$ are real numbers, and $\rho_{i}$ for $i=0, \ldots, n$ are coefficient functions.

Then, the family of (FO or IO) polynomials is [24]

$$
P=\{p(\cdot, \mathbf{q}): \mathbf{q} \in Q\}
$$

where $Q$ is the uncertainty bounding set. Most frequently, it is a multidimensional box which means that individual components of vector $\mathbf{q}$ are bounded by intervals.

The family of polynomials (2) is robustly stable if and only if $p(s, \mathbf{q})$ is stable for all $\mathbf{q} \in Q$. The selection of a specific method for investigation of robust stability depends mainly on the structure of uncertainty. Generally speaking, the higher level of relation among coefficients requires more complex robust stability analysis and consequently more sophisticated tools. There is a rich variety of tools for IO families available in the literature. For FO cases, the selection is more limited (e.g., the famous Kharitonov theorem is not valid for FO interval polynomials [46]), but several approaches have been already developed (see, e.g., [36-50]), and the number is still growing.

Nevertheless, one graphical method seems to be unique from the viewpoint of its universality. It is based on the combination of the value set concept and the well-known zero exclusion condition [24]. It can be applied to a wide range of uncertainty structures, from the simplest to very complicated ones. Moreover, it is utilizable also for various regions of stability (robust $D$-stability). The detailed information on parametric uncertainty and robust stability analysis and also examples of the typical value sets for the IO systems can be 
found in [24] and subsequently, for example, in [27, 28]. The works [36, 37, 41, 42, 46-48] have extended the idea of the value set concept also to FO uncertain polynomials (or quasi-polynomials $[49,50])$.

The value set for the family of polynomials (2) at the frequency $\omega \in \mathbb{R}$ is defined as [24]

$$
p(j \omega, Q)=\{p(j \omega, \mathbf{q}): \mathbf{q} \in Q\}
$$

which means that $p(j \omega, Q)$ is the image of $Q$ under $p(j \omega, \cdot)$. Practically speaking, the value sets can be constructed by substituting $s$ for $j \omega$, fixing $\omega$, and letting the vector of uncertain parameters $\mathbf{q}$ ranges over the set $Q$.

The zero exclusion condition for (Hurwitz) stability of the family of continuous-time polynomials (2) can be formulated [24]. Assume the invariant degree of polynomials in the family, pathwise-connected uncertainty bounding set $Q$, continuous coefficient functions $\rho_{k}(\mathbf{q})$ for $k=0,1,2, \ldots, n$ and at least one stable member $p\left(s, \mathbf{q}^{0}\right)$. Then, the family $P$ is robustly stable if and only if the origin of the complex plane (zero point) is excluded from the value set $p(j \omega, Q)$ at all frequencies $\omega \geq 0$, that is, $P$ is robustly stable if and only if

$$
0 \notin p(j \omega, Q) \quad \forall \omega \geq 0 .
$$

In works $[37,41,42,46,47]$, the value sets for the FO families of polynomials are constructed principally on the basis of the fact that the fractional power of $j \omega$ can be expressed as

$$
(j \omega)^{\alpha}=\omega^{\alpha}\left(\cos \frac{\pi}{2} \alpha+j \sin \frac{\pi}{2} \alpha\right)
$$

and on the subsequent analysis of vertices and exposed edges.

In this paper, the visualization of the value set is based on suitable sampling (gridding) of the uncertain parameters and on direct calculation of related partial points of the value sets for a supposed frequency range. This sampling (brute-force) method is easily applicable for the computation of the value sets of a polynomial family even with complicated uncertainty structures [48] (or even for quasi-polynomial families $[49,50])$. Then, the robust stability can be analyzed via standard zero exclusion theorem with the necessary and sufficient condition. In fact, the main advantage of the direct sampling lies in the applicability to complex uncertainty structures where a lack of more sophisticated methods is. However, the cost for the simplicity is a long computational time for a high number of uncertain parameters.

\section{Robust Stability Analysis under Unstructured Multiplicative Uncertainty}

The multiplicative uncertainty model is probably the most frequently used kind of the model with unstructured uncertainty. The other commonly used one is the additive model (see Section 4). Besides, the inverse versions of both multiplicative and additive models are available [29, 32-34].

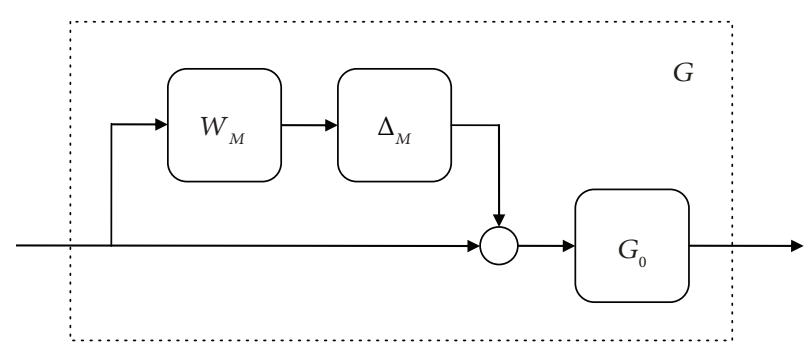

Figure 1: Plant with multiplicative uncertainty [55].

The multiplicative model is described by

$$
G(s)=\left[1+W_{M}(s) \Delta_{M}(s)\right] G_{0}(s),
$$

where $G(s)$ is an uncertain (perturbed) model, $G_{0}(s)$ represents a nominal model, $W_{M}(s)$ stands for a stable weight function representing uncertainty dynamics (i.e., distribution of the maximum amplitude of the uncertainty over the frequency), and $\Delta_{M}(s)$ means the uncertainty itself (i.e., uncertain information on actual magnitude and phase of perturbation), which can be represented by an arbitrary stable function that fulfills the inequality:

$$
\left\|\Delta_{M}(s)\right\|_{\infty} \leq 1 \Rightarrow\left|\Delta_{M}(j \omega)\right| \leq 1 \quad \forall \omega
$$

The requirement of the stability of $\Delta_{M}(s)$ may be replaced by the presumption that all members of the family $G(s)$ have the same amount of right-hand (unstable) poles. In other words, $G(s)$ and $G_{0}(s)$ have the same amount of right-hand poles for all $\Delta_{M}(s)$. However, the assumption of the stable perturbations is preferred in practice [29].

The diagram of the multiplicative uncertainty, which corresponds to (6), is shown in Figure 1.

The key part of multiplicative model creation (as will be demonstrated in the examples below) consists in the selection of a suitable nominal model and a weight function. For the weight function, the following inequality must be fulfilled:

$$
\left|\frac{G(j \omega)}{G_{0}(j \omega)}-1\right| \leq\left|W_{M}(j \omega)\right| \quad \forall \omega,
$$

where the left side represents a normalized perturbation (relative error).

The closed-loop system with the unstructured multiplicative uncertainty plant is robustly stable if and only if $[29,30]$

$$
\left\|W_{M}(s) T_{0}(s)\right\|_{\infty}<1
$$

where $T_{0}(s)$ stands for a complementary sensitivity function given by

$$
T_{0}(s)=\frac{L_{0}(s)}{1+L_{0}(s)},
$$




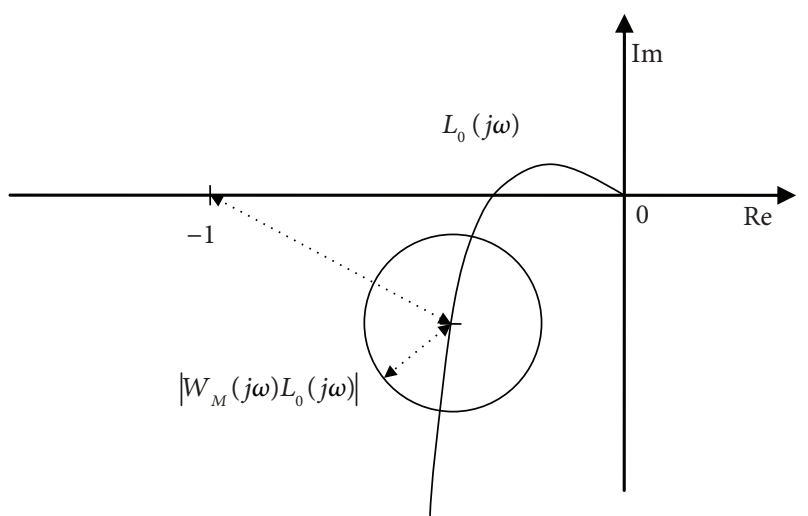

FIGURE 2: Graphical interpretation of robust stability condition for multiplicative uncertainty [55].

with $L_{0}(s)$ representing the open-loop transfer function:

$$
L_{0}(s)=C(s) G_{0}(s)
$$

The fundamental inequality condition (9) can be rewritten to the form:

$\left|\frac{W_{M}(j \omega) L_{0}(j \omega)}{1+L_{0}(j \omega)}\right|<1 \quad \forall \omega \Rightarrow\left|W_{M}(j \omega) L_{0}(j \omega)\right|<\left|L_{0}(j \omega)-(-1)\right| \quad \forall \omega$,

which means that the closed-loop system is robustly stable if and only if the envelope of the Nyquist diagrams with a radius of $\left|W_{M}(j \omega) L_{0}(j \omega)\right|$ and center $L_{0}(j \omega)$ does not include the critical point $[-1,0 j]$. The visualization of this condition is shown in Figure 2.

Besides, the basic form of the robust stability condition (9) has also its equivalent alternative formulation:

$$
\left|T_{0}(j \omega)\right|<\frac{1}{\left|W_{M}(j \omega)\right|} \quad \forall \omega
$$

which reflects an upper bound restriction on complementary sensitivity and which is suitable for visualization by using a Bode magnitude plot.

\section{Robust Stability Analysis under Unstructured Additive Uncertainty}

As it has been already mentioned, the unstructured additive uncertainty represents the commonly used alternative for describing the uncertain systems.

The additive uncertainty model can be written as

$$
G(s)=G_{0}(s)+W_{A}(s) \Delta_{A}(s)
$$

where $G(s), G_{0}(s)$, and $\Delta_{M}(s)$ have the same meaning as in the multiplicative case and $W_{A}(s)$ represent a stable weight function representing uncertainty dynamics (analogically to the multiplicative case).

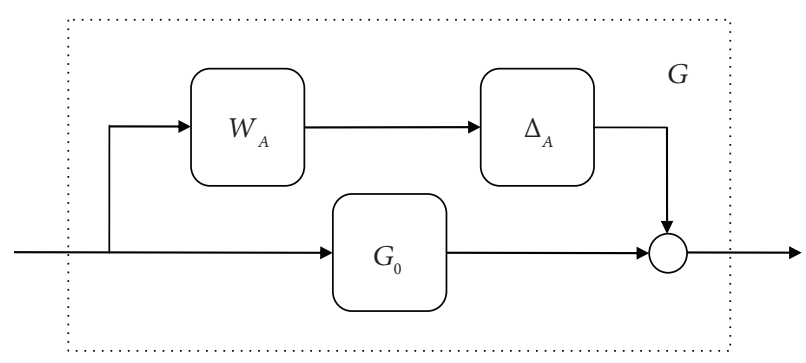

FIgURe 3: Plant with additive uncertainty.

The graphical representation of the additive uncertainty model, corresponding to the (14), is depicted in Figure 3.

The weight function for the additive uncertainty must fulfill the following inequality:

$$
\left|G(j \omega)-G_{0}(j \omega)\right| \leq\left|W_{A}(j \omega)\right| \quad \forall \omega .
$$

The multiplicative and additive uncertainty descriptions are equivalent if

$$
\left|W_{A}(j \omega)\right|=\left|G_{0}(j \omega)\right| \cdot\left|W_{M}(j \omega)\right| \quad \forall \omega .
$$

The closed-loop system with the unstructured additive uncertainty plant is robustly stable if and only if $[29,30]$

$$
\left\|W_{A}(s) C(s) S_{0}(s)\right\|_{\infty}<1
$$

where $C(s)$ is a controller and $S_{0}(s)$ represents a sensitivity function defined as

$$
S_{0}(s)=\frac{1}{1+L_{0}(s)}=\frac{1}{1+C(s) G_{0}(s)}
$$

A graphical interpretation of the fundamental inequality condition (17) can be obtained from its adjustment:

$$
\left|\frac{W_{A}(j \omega) C(j \omega)}{1+L_{0}(j \omega)}\right|<1 \quad \forall \omega \Rightarrow\left|W_{A}(j \omega) C(j \omega)\right|<\left|L_{0}(j \omega)-(-1)\right| \quad \forall \omega .
$$

It means that the closed-loop system is robustly stable if and only if the envelope of the Nyquist diagrams with a radius of $\left|W_{A}(j \omega) C(j \omega)\right|$ and center $L_{0}(j \omega)$ does not include the critical point $[-1,0 j]$. This condition is depicted in Figure 4.

Furthermore, the robust stability condition (17) can also have the equivalent alternative formulation, representing an upper bound restriction, convenient for a Bode magnitude plot:

$$
\left|C(j \omega) S_{0}(j \omega)\right|<\frac{1}{\left|W_{A}(j \omega)\right|} \quad \forall \omega .
$$




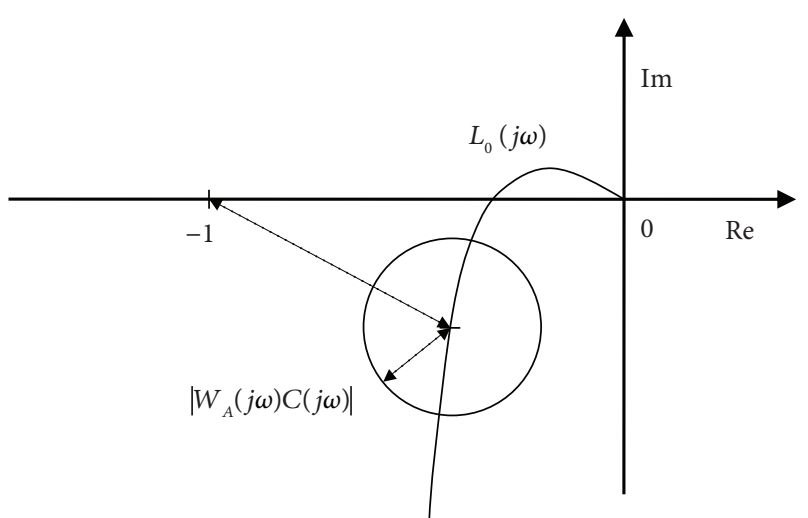

FIGURE 4: Graphical interpretation of robust stability condition for additive uncertainty.

\section{Illustrative Examples}

The robust stability of the specific FO feedback control loops with either the plant with parametric uncertainty, the plant with unstructured multiplicative uncertainty, or the plant with unstructured additive uncertainty, and a selected controller is investigated within this section. Moreover, a possible way for the construction of the unstructured (multiplicative or additive) model for the originally parametrically uncertain system is also included.

5.1. Example 1. Consider a FO plant with integrating behavior (inspired by the IO version from [56] and its FO modification in [57])

$$
\begin{aligned}
G\left(s, a_{1}, a_{2}\right) & =\frac{1}{s\left(s^{2.1}+a_{2} s^{1.05}+a_{1}\right)} \\
& =\frac{1}{s^{3.1}+a_{2} s^{2.05}+a_{1} s},
\end{aligned}
$$

where $a_{1} \in[3,5]$ and $a_{2} \in[1,3]$.

The aim is to verify if the family of systems (21) is robustly stabilized by the feedback unit proportional controller:

$$
C(s)=P=1,
$$

and the analysis is going to be performed successively for the originally parametrically uncertain family (21), unstructured multiplicative model (27), and unstructured additive model (29) which are constructed to cover the original one. Furthermore, the critical controller gain $P$ (for robust stability border) should be found for all cases.

Note that the robust stability conditions for both types of studied unstructured uncertainties are valid even for the unstable (or integrating) plants as long as the number of right-hand (unstable) poles remains the same for each member of the family $\mathrm{G}(\mathrm{s})$ [29].

5.1.1. Parametric Uncertainty. Thus, first, the direct robust stability test of the parametric uncertainty plant (21) with the controller (22) is discussed. The family of FO closedloop characteristic polynomials is

$p_{C L}\left(s, a_{1}, a_{2}\right)=s^{3.1}+a_{2} s^{2.05}+a_{1} s+P, \quad a_{1} \in[3,5], a_{2} \in[1,3]$.

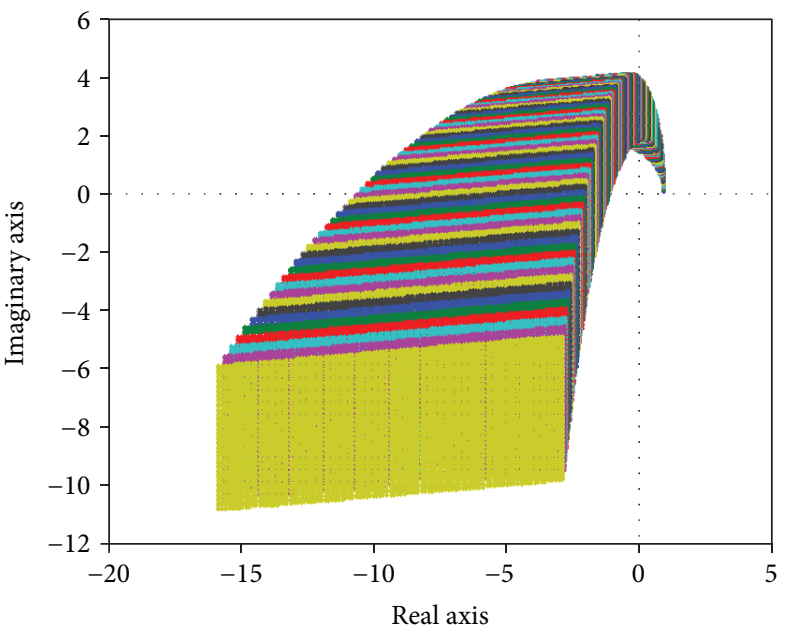

FIGURE 5: Value sets of FO interval polynomial (23)—gridding [55].

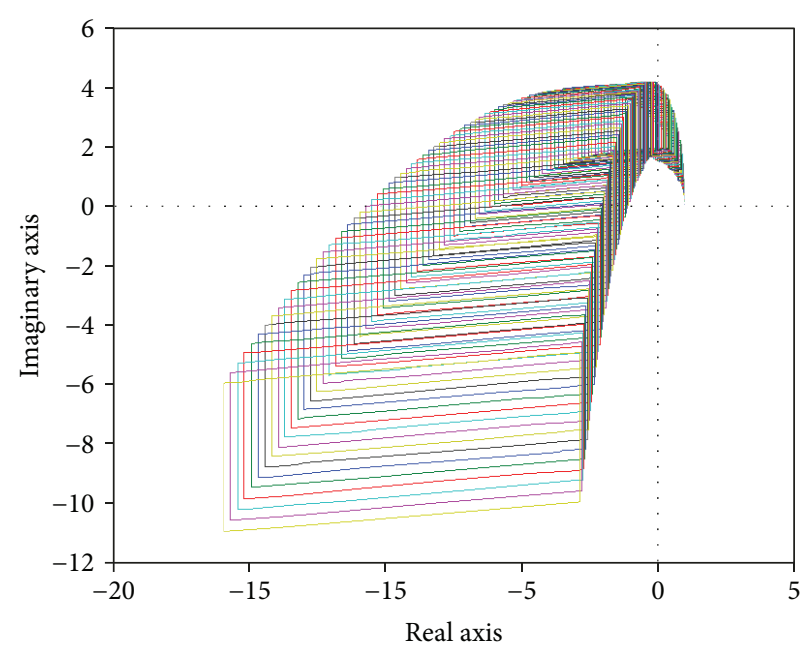

FIGURE 6: Value sets of FO interval polynomial (23)—convex hulls [55].

The value sets are plotted in Figure 5 for the frequency range from 0 to 2.5 with the step 0.02 . Figure 5 is based on sampling of the uncertain parameters (both with the step 0.02 ) and direct calculation of related partial value set points. The same plot but with just convex hulls of the obtained convex tetragons can be seen in Figure 6. Anyway, the family (23) is robustly stable, because it contains a stable member and the origin of the complex plane (zero point) is excluded from the calculated value sets.

Next, instead of working directly with the parametric system, the FO models with unstructured multiplicative or additive uncertainty are going to be created and used.

5.1.2. Unstructured Multiplicative Uncertainty. The construction of the multiplicative model (6) means the selection of a nominal model $G_{0}(s)$ and a weight function $W_{M}(s)$. The FO nominal system is simply supposed as 


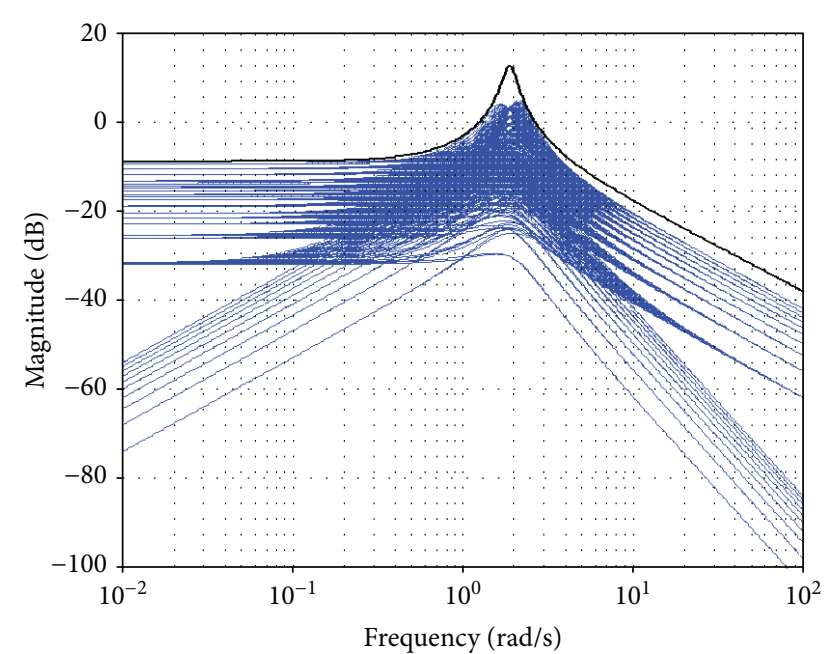

FIgURE 7: Bode magnitude plots-set of FO normalized perturbations and weight function (26) for the multiplicative uncertainty model [55].

the one with the average values of uncertain parameters from (21):

$$
G_{0}(s)=\frac{1}{s^{3.1}+2 s^{2.05}+4 s}
$$

Subsequently, the appropriate weight function, which can be considered as the envelope of uncertainty, has to be selected in order to fulfill the inequality (8), that is, the magnitude of the weight function has to cover the magnitudes of all normalized perturbations, even for the worst possible case of uncertainty in the model (21), from the upper side for all frequencies. Figure 7 shows the Bode magnitude plots of the set of normalized perturbations (for all combinations of uncertain parameters with chosen steps $a_{1}=3: 0.1: 5$ and $a_{2}=1: 0.1: 3$ ) (see the blue curves). Moreover, the Bode magnitude plot of the suitable weight function (26) is also included in Figure 7. The convenient weight function (26) is chosen as

$$
W_{M}(s)=\frac{0.35(s+1)}{(0.53 s)^{2}+2 \xi 0.53 s+1},
$$

with the damping ratio $\xi=0.09$, that is, its final form is

$$
W_{M}(s)=\frac{0.35 s+0.35}{0.2809 s^{2}+0.0954 s+1} .
$$

Thus, the final model of the FO system with unstructured multiplicative uncertainty is

$$
\begin{aligned}
G(s) & =\left[1+W_{M}(s) \Delta_{M}(s)\right] G_{0}(s) \\
\left\|\Delta_{M}(s)\right\|_{\infty} & \leq 1 \\
G_{0}(s) & =\frac{1}{s^{3.1}+2 s^{2.05}+4 s} \\
W_{M}(s) & =\frac{0.35 s+0.35}{0.2809 s^{2}+0.0954 s+1} .
\end{aligned}
$$

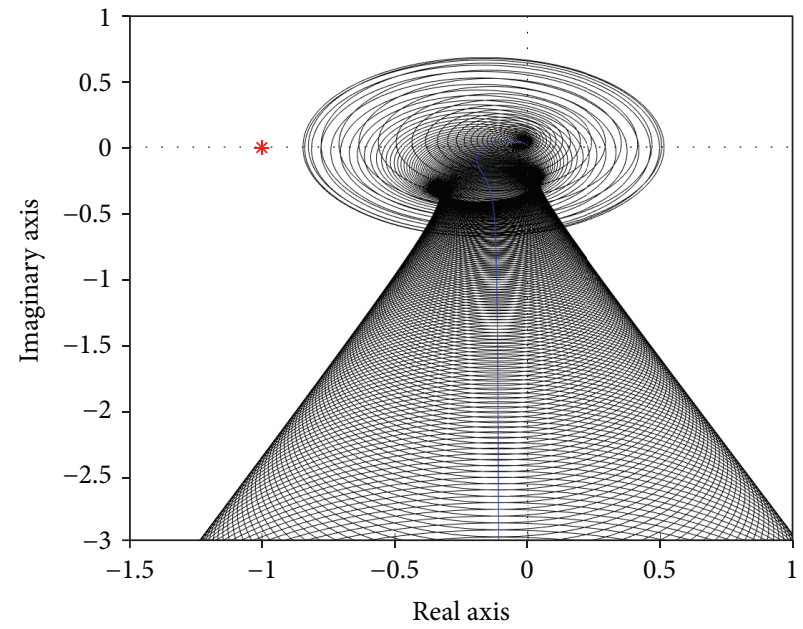

Figure 8: Envelope of Nyquist diagrams for FO plant family (27) and controller (22) [55].

Under the assumption of the unit controller (22), the envelope of the Nyquist diagrams given by circles with radius $\left|W_{M}(j \omega) L_{0}(j \omega)\right|$ around the Nyquist diagram of nominal $L_{0}(j \omega)$ (blue curve) is plotted in Figure 8. It can be clearly seen that the critical point $[-1,0 j]$ is excluded from the envelope and consequently the closed loop with the controller (22) and family of systems (27) is robustly stable.

5.1.3. Unstructured Additive Uncertainty. The procedure of constructing the additive model (14) is basically the same as for the previous multiplicative model, that is, a nominal model $G_{0}(s)$ and a weight function $W_{A}(s)$ have to be selected. The FO nominal system is assumed to be the same "averageparameter" system (24) as in the multiplicative case. Furthermore, the appropriate weight function fulfilling the inequality (15) has to be found.

The Bode magnitude plots of the perturbations $\mid G(j \omega)-$ $G_{0}(j \omega) \mid$ (for all combinations of uncertain parameters with chosen steps $a_{1}=3: 0.1: 5$ and $a_{2}=1: 0.1: 3$ ), represented by the blue curves again, together with the Bode magnitude plot of the selected weight function (28) are shown in Figure 9. This weight function is chosen as

$$
\begin{aligned}
W_{A}(s) & =\frac{0.09\left[(0.5 s)^{2}+16 \cdot 0.5 s+1\right]}{s(0.5 s+1)^{3}\left[(0.5 s)^{2}+0.5 s+1\right]} \\
& =\frac{0.0225 s^{2}+0.72 s+0.09}{0.03125 s^{6}+0.25 s^{5}+0.875 s^{4}+1.75 s^{3}+2 s^{2}+s}
\end{aligned}
$$

The specific weight (28) is obtained from the initial function $0.09 /\left[s(0.5 s+1)^{3}\right]$, which respects the basic shape of the requested magnitude Bode plot. Such initial weight is subsequently multiplied by a corrective function in order to lift the gain near the requested frequency. More details on the ideas behind the selection of the weights (applied to the IO systems) can be found in [58]. 


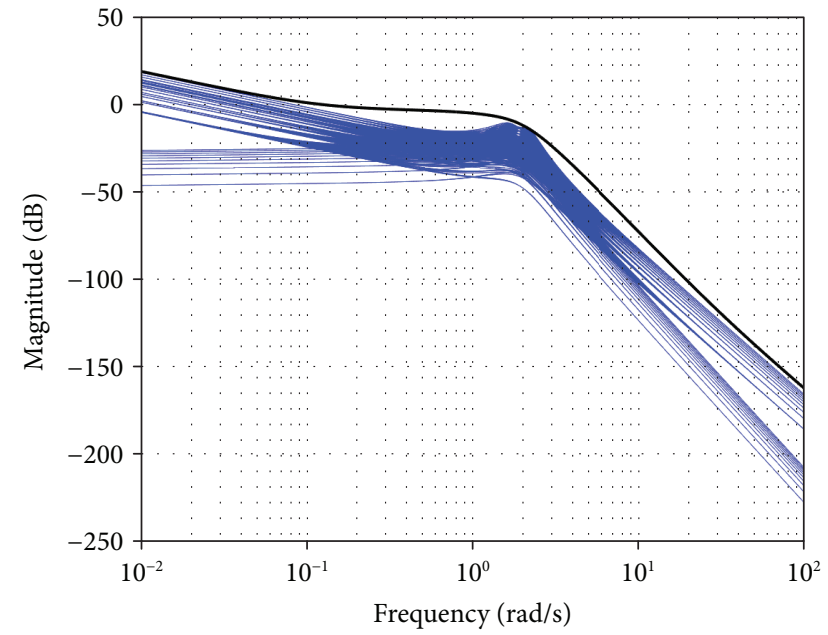

Figure 9: Bode magnitude plots-set of FO perturbations and weight function (28) for the additive uncertainty model.

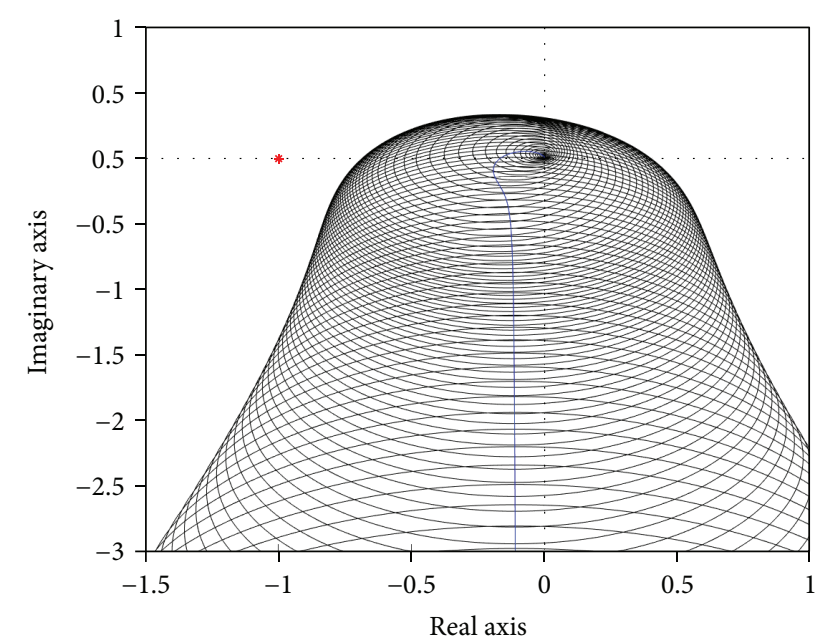

Figure 10: Envelope of Nyquist diagrams for FO plant family (29) and controller (22).

So, the final model of the FO system with unstructured additive uncertainty is

$$
\begin{aligned}
G(s) & =G_{0}(s)+W_{A}(s) \Delta_{A}(s), \\
\left\|\Delta_{A}(s)\right\|_{\infty} & \leq 1 \\
G_{0}(s) & =\frac{1}{s^{3.1}+2 s^{2.05}+4 s}, \\
W_{A}(s) & =\frac{0.0225 s^{2}+0.72 s+0.09}{0.03125 s^{6}+0.25 s^{5}+0.875 s^{4}+1.75 s^{3}+2 s^{2}+s} .
\end{aligned}
$$

As in the previous cases, suppose that the family (29) is in the feedback connection with the unit controller (22) and the aim is to decide on the robust stability. Figure 10 shows the envelope of the Nyquist diagrams given by the circles with radius $\left|W_{A}(j \omega) C(j \omega)\right|$ around the Nyquist diagram of

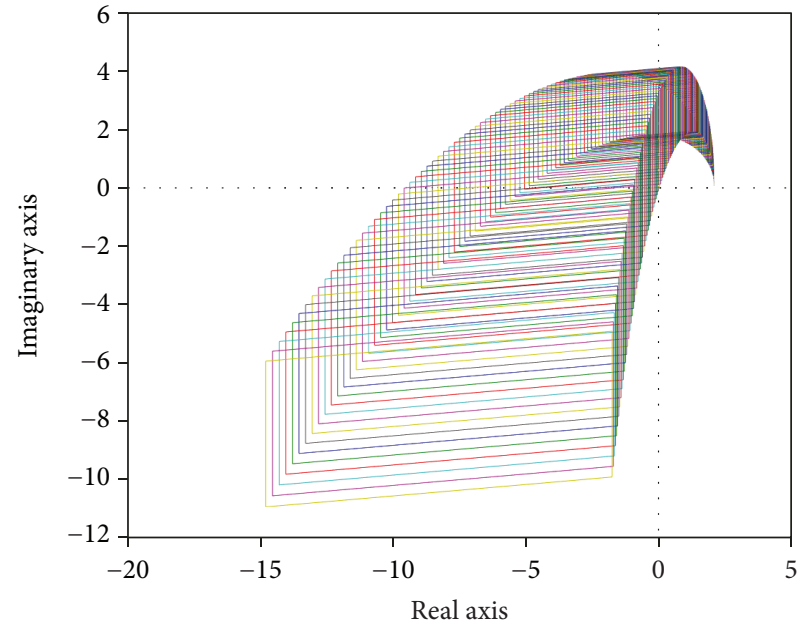

FIgURe 11: Value sets of FO interval polynomial (23) for $P=2.065$ [55].

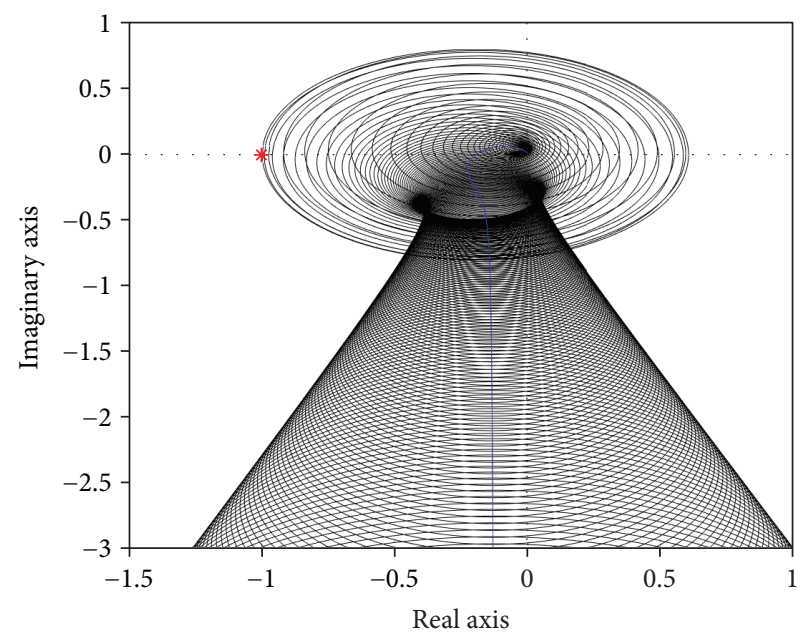

FIgURE 12: Envelope of Nyquist diagrams for FO plant family (27) and controller $P=1.18$ [55].

nominal $L_{0}(j \omega)$ (blue curve). Obviously, the critical point [ $-1,0 j]$ is excluded from the envelope and consequently the closed loop with the controller (22) and family of systems (29) is robustly stable.

5.1.4. Comparison and Discussion. So, all three robust stability results (for the system with parametric uncertainty, the system with unstructured multiplicative uncertainty, and the system with unstructured additive uncertainty) concur. However, it needs not to be true in all cases. Therefore, the following goal is to find the critical gain of the proportional controller which brings the feedback loop to the robust stability border.

First, the critical gain for the original system with parametric uncertainty (21) is near the value 2.065 (see Figure 11 where the value sets touch the complex plane origin for this $P$ ). Nonetheless, the critical gain for the constructed multiplicative model (27) is only about 1.18 and for the constructed additive model (29) is about 1.46 (again, see Figures 12 and 13 with the envelopes of the Nyquist diagrams 


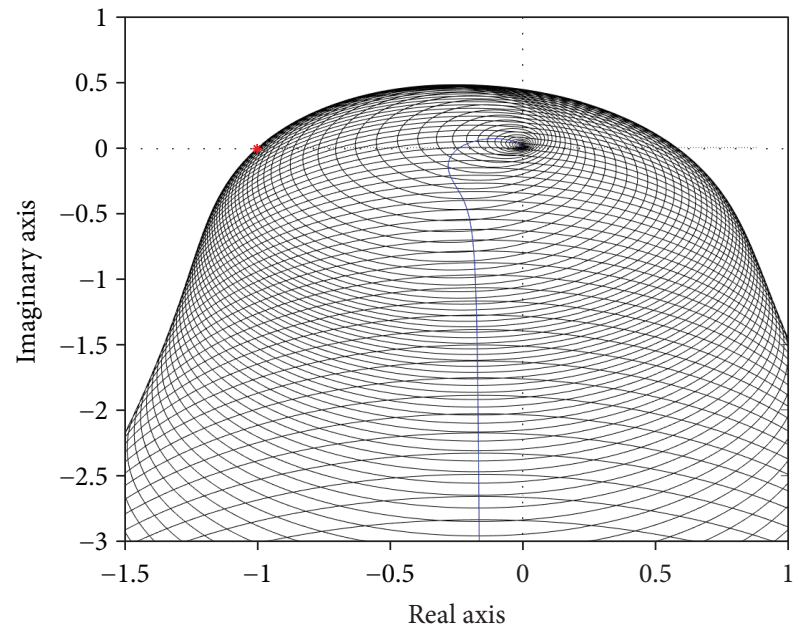

Figure 13: Envelope of Nyquist diagrams for FO plant family (29) and controller $P=1.46$.

touching the critical point $[-1,0 j]$ for the corresponding values of $P$ ).

The obtained outcomes indicate that one should be aware of potential conservatism in the investigation of robust stability when the (FO) system with parametric uncertainty is modelled as a (FO) system with unstructured (multiplicative or additive) uncertainty. One part of the discrepancy reason consists in an inexact approximation of the perturbations by the weight function. However, even if the weight function covered the perturbations as precisely as possible, the family of unstructured uncertainty systems still could contain some members which would not be stabilized because the perturbations satisfying $|\Delta(j \omega)| \leq 1$ at all frequencies are supposed. All in all, the necessary and sufficient robust stability condition can change to only sufficient one.

5.2. Example 2. Assume a FO plant adopted from [59]

$$
G\left(s, b_{0}, a_{0}, a_{1}, a_{2}\right)=\frac{b_{0}}{a_{2} s^{2.2}+a_{1} s^{0.9}+a_{0}},
$$

where all four parameters are supposed to vary $\pm 10 \%$ around the nominal values from [59]. That is, the uncertain parameters are $b_{0} \in[0.9,1.1], a_{0} \in[0.9,1.1], a_{1} \in[0.45,0.55]$, and $a_{2} \in[0.72,0.88]$.

Further, consider the FO $P I^{\lambda} D^{\mu}$ controller designed for the nominal plant in [60]

$$
\begin{aligned}
C(s) & =233.4234+\frac{22.3972}{s^{0.1}}+18.5274 s^{1.15} \\
& =\frac{233.4234 s^{0.1}+22.3972+18.5274 s^{1.25}}{s^{0.1}}
\end{aligned}
$$

and the goal is to analyze the robust stability of the feedback loop with this $P I^{\lambda} D^{\mu}$ controller and with plant affected by parametric uncertainty (30) or subsequently created unstructured multiplicative model (35).

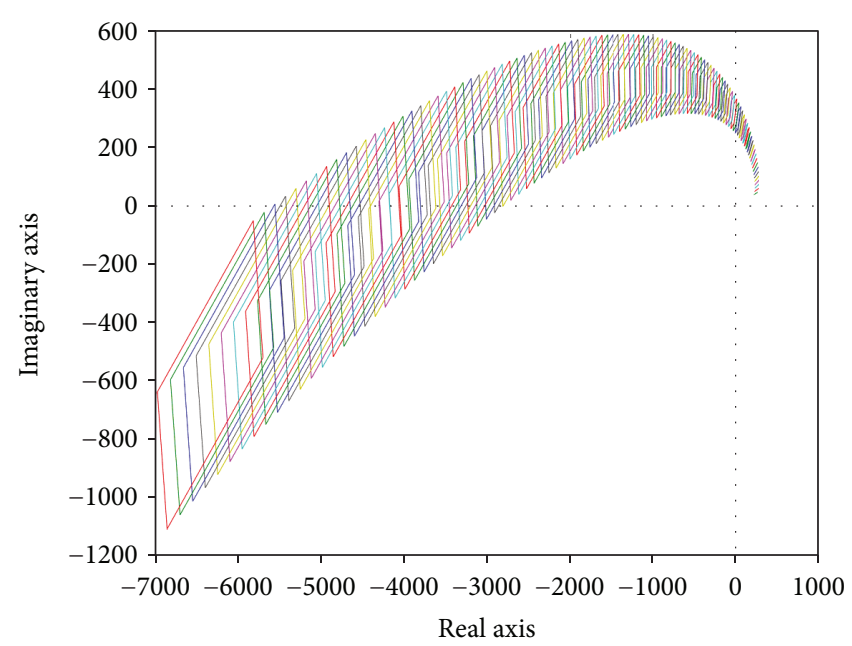

FIgURe 14: Value sets of the FO family of polynomials (32).

5.2.1. Parametric Uncertainty. As in the previous example, the parametric uncertainty case is studied in the first instance. Thus, the family of FO closed-loop characteristic polynomials is

$$
\begin{aligned}
& p_{C L}\left(s, b_{0}, a_{0}, a_{1}, a_{2}\right)= a_{2} s^{2.3}+a_{1} s+a_{0} s^{0.1}+233.4234 b_{0} s^{0.1} \\
&+18.5274 b_{0} s^{1.25}+22.3972 b_{0}=a_{2} s^{2.3} \\
&+18.5274 b_{0} s^{1.25}+a_{1} s \\
&+\left(a_{0}+233.4234 b_{0}\right) s^{0.1}+22.3972 b_{0}, \\
& b_{0} \in[0.9,1.1], a_{0} \in[0.9,1.1], a_{1} \in[0.45,0.55], a_{2} \in[0.72,0.88] .
\end{aligned}
$$

Figure 14 depicts the value sets for the frequency range from 0 to 50 with step 0.1 (the value set for $\omega=0$ is a short line in the positive real axis which is not observable in the presented view). As can be clearly seen, the polynomial family (32) (and consequently also the feedback loop with FO plant (30) and $P I^{\lambda} D^{\mu}$ controller (31)) is robustly stable, because the zero point is excluded from the computed value sets and the family contains a stable member.

5.2.2. Unstructured Multiplicative Uncertainty. Now, the attention is going to be paid to the unstructured multiplicative uncertainty case. The FO nominal system with the average values from (30) (i.e., directly the plant model from [59]) is considered, that is,

$$
G_{0}(s)=\frac{1}{0.8 s^{2.2}+0.5 s^{0.9}+1} .
$$

The Bode magnitude plots of the set of normalized perturbations (for all combinations of the parameters with chosen steps $b_{0}=0.9: 0.05: 1.1, a_{0}=0.9: 0.05: 1.1, a_{1}=$ $0.45: 0.025: 0.55$, and $\left.a_{2}=0.72: 0.04: 0.88\right)$ are shown in Figure 15 (blue curves). Furthermore, the same Figure 15 contains also the Bode magnitude plot of the weight function 


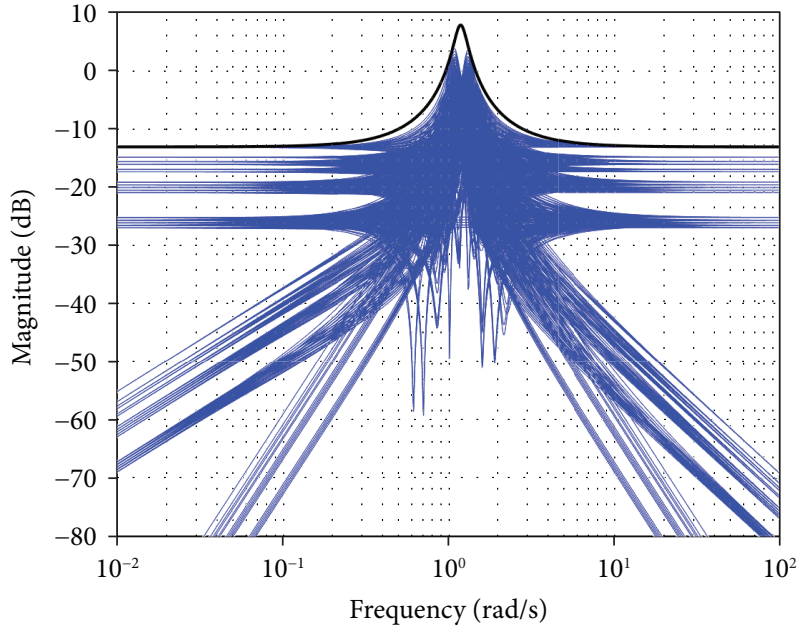

FIgURE 15: Bode magnitude plots-set of FO normalized perturbations and weight function (34).

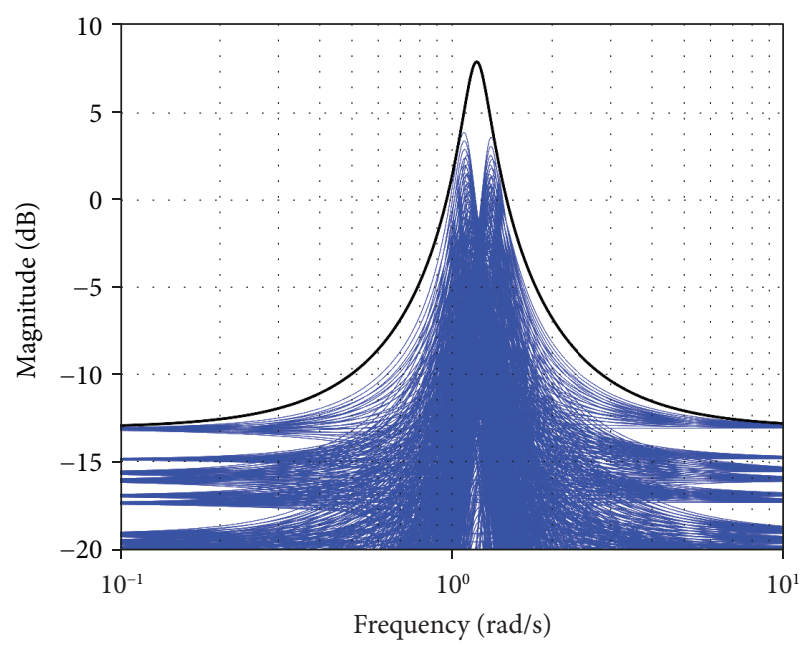

FIgURE 16: Zoomed version of Bode magnitude plots from Figure 15-set of FO normalized perturbations and weight function (34).

that has been selected, with respect to condition (8), as

$$
W_{M}(s)=\frac{0.223(0.845 s+1)^{2}}{(0.845 s)^{2}+2 \cdot 0.09 \cdot 0.845 s+1} \approx \frac{0.1592 s^{2}+0.3769 s+0.223}{0.714 s^{2}+0.1521 s+1} .
$$

Then, the zoomed version (both frequency and magnitude axes) of the same plots is shown in Figure 16.

So, the final model of the FO system with unstructured multiplicative uncertainty for the second example is

$$
\begin{aligned}
G(s) & =\left[1+W_{M 1}(s) \Delta_{M}(s)\right] G_{0}(s), \\
\left\|\Delta_{M}(s)\right\|_{\infty} & \leq 1 \\
G_{0}(s) & =\frac{1}{0.8 s^{2.2}+0.5 s^{0.9}+1}, \\
W_{M}(s) & =\frac{0.1592 s^{2}+0.3769 s+0.223}{0.714 s^{2}+0.1521 s+1} .
\end{aligned}
$$

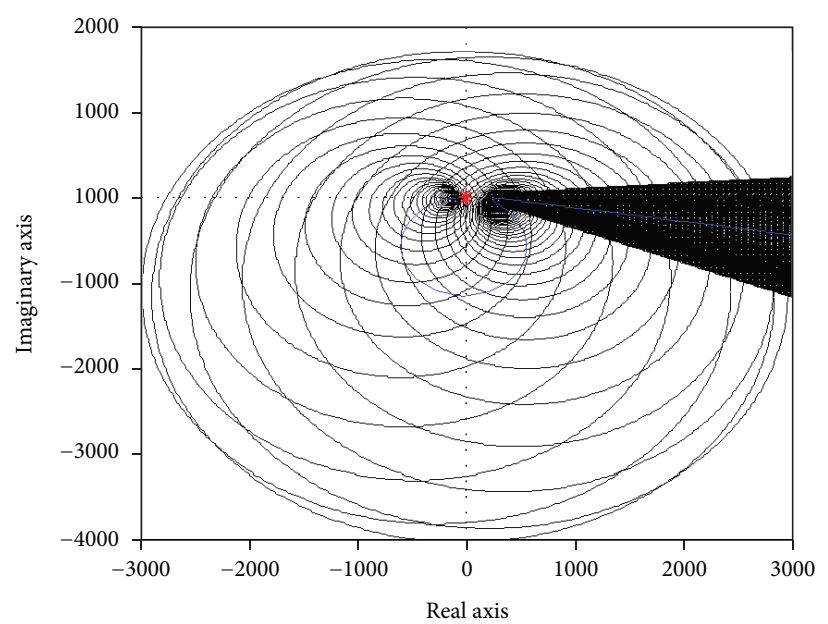

FIgURe 17: Envelope of Nyquist diagrams for FO plant family (35) and controller (31).

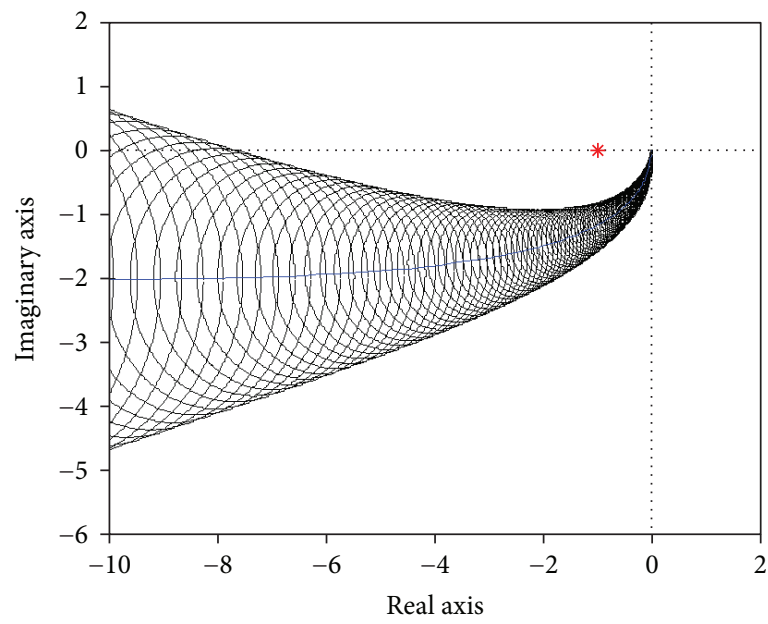

FIgURE 18: Envelope of Nyquist diagrams for FO plant family (35) and controller (31)—detailed view.

The robust stability test for the loop with this model (35) and $P I^{\lambda} D^{\mu}$ controller (31) follows. The envelope of the Nyquist diagrams is visualized in Figure 17, and closer look at the neighborhood of the critical point $[-1,0 j]$ is provided in Figure 18. Unfortunately, the point -1 is included in the envelope which means the closed-loop system is robustly unstable.

5.2.3. Comparison and Discussion. Despite the fact that the closed-loop system with the multiplicative uncertainty model (35) is robustly unstable, the original plant (30) with parametric uncertainty is robustly stabilized by the same $P I^{\lambda} D^{\mu}$ controller (31). The explanation of the discrepancy and conservatism in the robustness analysis can be found in Section 5.1.4 (i.e., an inexact approximation of the perturbations by the weight function and the character of the supposed perturbations itself). For this specific case, the visualization of the alternative form of the robust stability condition (13) from Figure 19 reveals that the problematic area is at the 


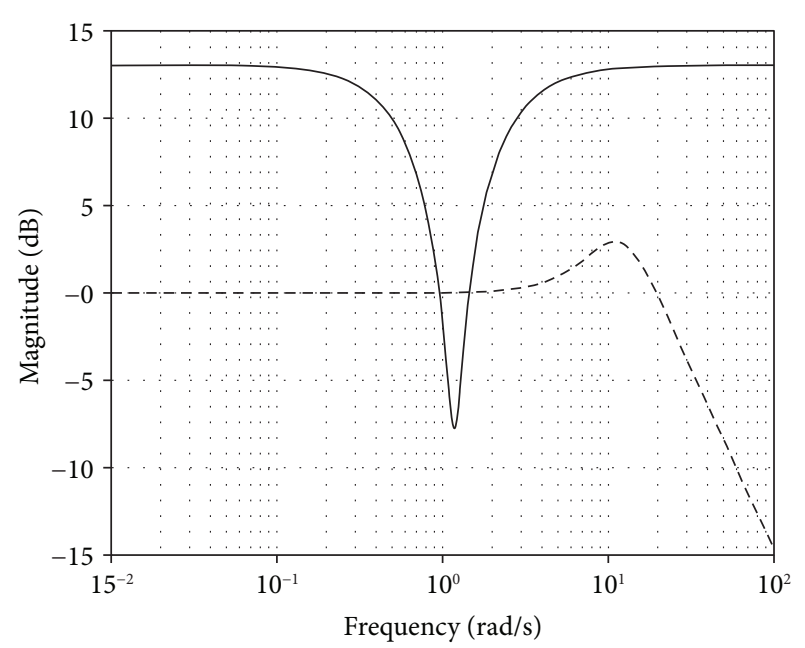

FIGURE 19: Visualization of robust stability condition in alternative form (13)-upper bound $1 /\left|W_{M}(j \omega)\right|$ (solid line) and complementary sensitivity $\left|T_{0}(j \omega)\right|$ (dashed line).

frequencies of the magnitude peak of the weight function (34) (see Figure 16).

\section{Conclusion}

The paper has been focused on three approaches to mathematical description and robust stability investigation of FO LTI systems under conditions of uncertainty. The parametric uncertainty is natural and advantageous from the viewpoint of relative simplicity. On the other hand, the unstructured (multiplicative or additive) uncertainty is favorable especially for unmodelled dynamics or nonlinearities and preferential for $H_{\infty}$-based control design methods. The presented examples have demonstrated analysis of robust stability for control loops with various kinds of $\mathrm{FO}$ uncertain systems including a technique for creation of the multiplicative or additive uncertainty model from the plant with parametric uncertainty by selecting a suitable nominal model and a weight function. Moreover, the potential discrepancies in obtained closedloop robust stability results (while using various plant models and $P$ or $P I^{\lambda} D^{\mu}$ controller) have been discussed.

\section{Data Availability}

All relevant data are available within the manuscript.

\section{Disclosure}

A preliminary version of this paper was presented at the IEEE Multi-Conference on Systems and Control 2016 [55].

\section{Conflicts of Interest}

The authors declare that there is no conflict of interest regarding the publication of this paper.

\section{Acknowledgments}

The work was supported by the European Regional Development Fund under the project CEBIA-Tech Instrumentation no. CZ.1.05/2.1.00/19.0376 and by the Ministry of Education, Youth and Sports of the Czech Republic within the National Sustainability Programme Project no. LO1303 (MSMT7778/2014). This assistance is very gratefully acknowledged.

\section{References}

[1] J. T. Machado, V. Kiryakova, and F. Mainardi, "Recent history of fractional calculus," Communications in Nonlinear Science and Numerical Simulation, vol. 16, no. 3, pp. 1140-1153, 2011.

[2] R. E. Gutiérrez, J. M. Rosário, and J. Tenreiro Machado, "Fractional order calculus: basic concepts and engineering applications," Mathematical Problems in Engineering, vol. 2010, Article ID 375858, 19 pages, 2010.

[3] I. Podlubný, Fractional Differential Equations, Academic Press, San Diego, CA, USA, 1999.

[4] K. S. Miller and B. Ross, An Introduction to the Fractional Calculus and Fractional Differential Equations, John Wiley and Sons, New York, NY, USA, 1993.

[5] K. B. Oldham and J. Spanier, Fractional Calculus: Theory and Applications of Differentiation and Integration to Arbitrary Order, Academic Press, New York-London, 1974.

[6] M. F. M. Lima, J. A. T. Machado, and M. Crisóstomo, "Experimental signal analysis of robot impacts in a fractional calculus perspective," Journal of Advanced Computational Intelligence and Intelligent Informatics, vol. 11, no. 9, pp. 1079-1085, 2007.

[7] M. F. Silva, J. A. T. Machado, and A. M. Lopes, "Fractional order control of a hexapod robot," Nonlinear Dynamics, vol. 38, no. 1-4, pp. 417-433, 2004.

[8] R. Panda and M. Dash, "Fractional generalized splines and signal processing," Signal Processing, vol. 86, no. 9, pp. 23402350, 2006.

[9] A. S. Elwakil, "Fractional-order circuits and systems: an emerging interdisciplinary research area," IEEE Circuits and Systems Magazine, vol. 10, no. 4, pp. 40-50, 2010.

[10] T. Kaczorek and K. Rogowski, Fractional Linear Systems and Electrical Circuits, Springer International Publishing, Cham, Switzerland, 2015.

[11] B. T. Krishna and K. V. V. S. Reddy, "Active and passive realization of fractance device of order 1/2," Active and Passive Electronic Components, vol. 2008, Article ID 369421, 5 pages, 2008.

[12] R. L. Magin and M. Ovadia, "Modeling the cardiac tissue electrode interface using fractional calculus," Journal of Vibration and Control, vol. 14, no. 9-10, pp. 1431-1442, 2008.

[13] N. Heymans, "Dynamic measurements in long-memory materials: fractional calculus evaluation of approach to steady state," Journal of Vibration and Control, vol. 14, no. 9-10, pp. 1587-1596, 2008.

[14] A. G. Radwan, K. Moaddy, K. N. Salama, S. Momani, and I. Hashim, "Control and switching synchronization of fractional order chaotic systems using active control technique," Journal of Advanced Research, vol. 5, no. 1, pp. 125-132, 2014.

[15] Y. Chen, I. Petráš, and D. Xue, "Fractional order control - a tutorial," in 2009 American Control Conference, St. Louis, MO, USA, June 2009. 
[16] I. Petráš, "Stability of fractional-order systems with rational orders: a survey," Fractional Calculus \& Applied Analysis, vol. 12, no. 3, pp. 269-298, 2009.

[17] R. Matušů, "Application of fractional order calculus to control theory," International Journal of Mathematical Models and Methods in Applied Sciences, vol. 5, no. 7, pp. 1062-1069, 2011.

[18] M. Axtell and M. E. Bise, "Fractional calculus applications in control systems," in IEEE Conference on Aerospace and Electronics, Dayton, OH, USA, May 1990.

[19] Z. Gao, "Robust stability criterion for fractional-order systems with interval uncertain coefficients and a time-delay," ISA Transactions, vol. 58, pp. 76-84, 2015.

[20] A. Tepljakov, E. A. Gonzalez, E. Petlenkov, J. Belikov, C. A. Monje, and I. Petráš, "Incorporation of fractional-order dynamics into an existing PI/PID DC motor control loop," ISA Transactions, vol. 60, pp. 262-273, 2016.

[21] S. E. Hamamci, "Stabilization using fractional order PI and PID controllers," Nonlinear Dynamics, vol. 51, no. 1-2, pp. 329-343, 2008.

[22] S. E. Hamamci and M. Koksal, "Calculation of all stabilizing fractional-order PD controllers for integrating time delay systems," Computers \& Mathematics with Applications, vol. 59, no. 5, pp. 1621-1629, 2010.

[23] I. Podlubný, "Fractional-order systems and $P I^{\lambda} D^{\mu}$-controllers," IEEE Transactions on Automatic Control, vol. 44, no. 1, pp. 208-214, 1999.

[24] B. R. Barmish, New Tools for Robustness of Linear Systems, Macmillan, New York, NY, USA, 1994.

[25] S. P. Bhattacharyya, H. Chapellat, and L. H. Keel, Robust Control: The Parametric Approach, Prentice Hall, Englewood Cliffs, NJ, USA, 1995.

[26] S. P. Bhattacharyya, A. Datta, and L. H. Keel, Linear Control Theory: Structure, Robustness, and Optimization, CRC Press, Taylor \& Francis Group, USA, 2009.

[27] R. Matušů and R. Prokop, "Graphical analysis of robust stability for systems with parametric uncertainty: an overview," Transactions of the Institute of Measurement and Control, vol. 33, no. 2, pp. 274-290, 2011.

[28] R. Matušů and R. Prokop, "Robust stability analysis for systems with real parametric uncertainty: implementation of graphical tests in Matlab," International Journal of Circuits, Systems and Signal Processing, vol. 7, no. 1, pp. 26-33, 2013.

[29] S. Skogestad and I. Postlethwaite, Multivariable Feedback Control: Analysis and Design, John Wiley and Sons, Chichester, UK, 2005.

[30] J. Doyle, B. Francis, and A. Tannenbaum, Feedback Control Theory, Macmillan, New York, USA, 1992.

[31] V. Kučera, "Polynomial control: past, present, and future," International Journal of Robust and Nonlinear Control, vol. 17, no. 8, pp. 682-705, 2007.

[32] R. Matušů, R. Prokop, and L. Pekař, "Parametric and unstructured approach to uncertainty modelling and robust stability analysis," International Journal of Mathematical Models and Methods in Applied Sciences, vol. 5, no. 6, pp. 1011-1018, 2011.

[33] R. Matušů, B. Şenol, and C. Yeroğlu, "Modelling and robust stability analysis of systems with unstructured multiplicative uncertainty," in Recent Advances in Systems-Proceedings of the 19th International Conference on Systems, Zakynthos, Greece, 2015.
[34] R. Matušů, B. Şenol, and C. Yeroğlu, "Linear systems with unstructured multiplicative uncertainty: modeling and robust stability analysis," PloS One, vol. 12, no. 7, p. e0181078, 2017.

[35] D. Gorinevsky and G. Stein, "Structured uncertainty analysis of robust stability for multidimensional array systems," IEEE Transactions on Automatic Control, vol. 48, no. 9, pp. 15571568, 2003.

[36] B. Senol, A. Ates, B. Baykant Alagoz, and C. Yeroglu, "A numerical investigation for robust stability of fractionalorder uncertain systems," ISA Transactions, vol. 53, no. 2, pp. 189-198, 2014.

[37] C. Yeroğlu and B. Şenol, "Investigation of robust stability of fractional order multilinear affine systems: $2 q$-convex parpolygon approach," Systems \& Control Letters, vol. 62, no. 10, pp. 845-855, 2013.

[38] J.-G. Lu and Y. Chen, "Stability and stabilization of fractionalorder linear systems with convex polytopic uncertainties," Fractional Calculus \& Applied Analysis, vol. 16, no. 1, 2013.

[39] B. Şenol and C. Yeroğlu, "Frequency boundary of fractional order systems with nonlinear uncertainties," Journal of The Franklin Institute, vol. 350, no. 7, pp. 1908-1925, 2013.

[40] C. Li and J. Wang, "Robust stability and stabilization of fractional order interval systems with coupling relationships: the $0<\alpha<1$ case," Journal of The Franklin Institute, vol. 349, no. 7, pp. 2406-2419, 2012.

[41] B. Şenol and C. Yeroğlu, "Robust stability analysis of fractional order uncertain polynomials," in Proceedings of the 5th IFAC Workshop on Fractional Differentiation and its Applications, Nanjing, China, 2012.

[42] B. Şenol and C. Yeroğlu, "Computation of the value set of fractional order uncertain polynomials: a 2q convex parpolygonal approach," in 2012 IEEE International Conference on Control Applications, Dubrovnik, Croatia, October 2012.

[43] C. Yeroğlu and N. Tan, "Classical controller design techniques for fractional order case," ISA Transactions, vol. 50, no. 3, pp. 461-472, 2011.

[44] Z. Liao, C. Peng, W. Li, and Y. Wang, "Robust stability analysis for a class of fractional order systems with uncertain parameters," Journal of The Franklin Institute, vol. 348, no. 6, pp. 1101-1113, 2011.

[45] K. Akbari Moornani and M. Haeri, "Robust stability testing function and Kharitonov-like theorem for fractional order interval systems," IET Control Theory and Applications, vol. 4, no. 10, pp. 2097-2108, 2010.

[46] N. Tan, Ö. Faruk Özgüven, and M. Mine Özyetkin, "Robust stability analysis of fractional order interval polynomials," ISA Transactions, vol. 48, no. 2, pp. 166-172, 2009.

[47] C. Yeroğlu, M. Mine Özyetkin, and N. Tan, "Frequency response computation of fractional order interval transfer functions," International Journal of Control, Automation, and Systems, vol. 8, no. 5, pp. 1009-1017, 2010.

[48] R. Matušů, B. Şenol, and L. Pekař, "Robust stability of fractional order polynomials with complicated uncertainty structure," PloS One, vol. 12, no. 6, p. e0180274, 2017.

[49] R. Matušů and R. Prokop, "Robust stability of fractional order time-delay control systems: a graphical approach," Mathematical Problems in Engineering, vol. 2015, Article ID 847210, 9 pages, 2015.

[50] K. Akbari Moornani and M. Haeri, "On robust stability of LTI fractional-order delay systems of retarded and neutral type," Automatica, vol. 46, no. 2, pp. 362-368, 2010. 
[51] I. Petráš, Y. Chen, and B. M. Vinagre, “A robust stability test procedure for a class of uncertain LTI fractional order systems," in Proceedings of the International Carpathian Control Conference, Malenovice, Czech Republic, 2002.

[52] Y. Ma, J.-G. Lu, W. Chen, and Y. Chen, "Robust stability bounds of uncertain fractional-order systems," Fractional Calculus and Applied Analysis, vol. 17, no. 1, 2014.

[53] J. Lu, Y. Ma, and W. Chen, "Maximal perturbation bounds for robust stabilizability of fractional-order systems with norm bounded perturbations," Journal of The Franklin Institute, vol. 350, no. 10, pp. 3365-3383, 2013.

[54] Z. Jiao and Y. Zhong, "Robust stability for fractional-order systems with structured and unstructured uncertainties," Computers \& Mathematics with Applications, vol. 64, no. 10, pp. 3258-3266, 2012.

[55] R. Matušů and B. Şenol, "Two approaches to description and robust stability analysis of fractional order uncertain systems," in 2016 IEEE Conference on Control Applications (CCA), pp. 1244-1249, Buenos Aires, Argentina, September 2016.

[56] R. S. Burns, Advanced Control Engineering, ButterworthHeinemann, Oxford, UK, 2001.

[57] B. Şenol, R. Matušů, and C. Yeroğlu, "Robust stability analysis of fractional order systems with unstructured multiplicative uncertainty (Yapısız çarpimsal belirsizlik içeren kesir dereceli sistemlerin dayanikli kararlilik analizi)," in Proceedings of the Turkish National Conference on Automatic Control TOK’2015, Denizli, Turkey, 2015.

[58] R. Matušů and B. Şenol, "Description and analysis of systems with unstructured additive uncertainty," in Cybernetics Approaches in Intelligent Systems. CoMeSySo 2017. Advances in Intelligent Systems and Computing, vol. 661, pp. 1-9, Springer International Publishing AG, Switzerland.

[59] I. Podlubný, Fractional-Order Systems and Fractional-Order Controllers, Slovak Academy of Sciences, Institute of Experimental Physics, UEF-03-94, Košice, Slovak Republic, 1994.

[60] C. Zhao, D. Xue, and Y. Chen, "A fractional order PID tuning algorithm for a class of fractional order plants," in IEEE International Conference on Mechatronics and Automation, Niagara Falls, Canada, 2005. 


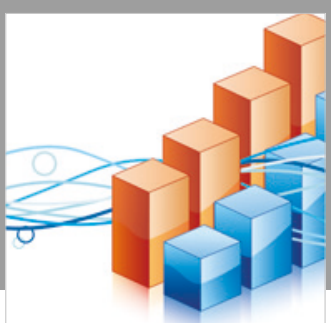

Advances in

Operations Research

\section{-n-m}
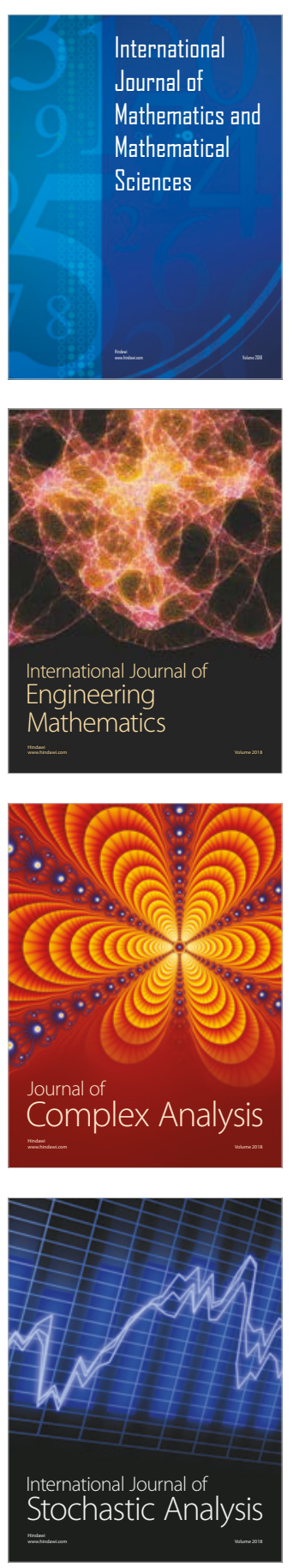
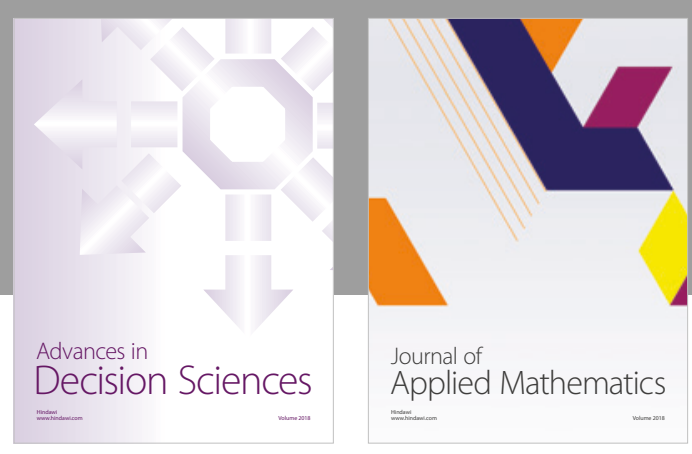

Journal of

Applied Mathematics
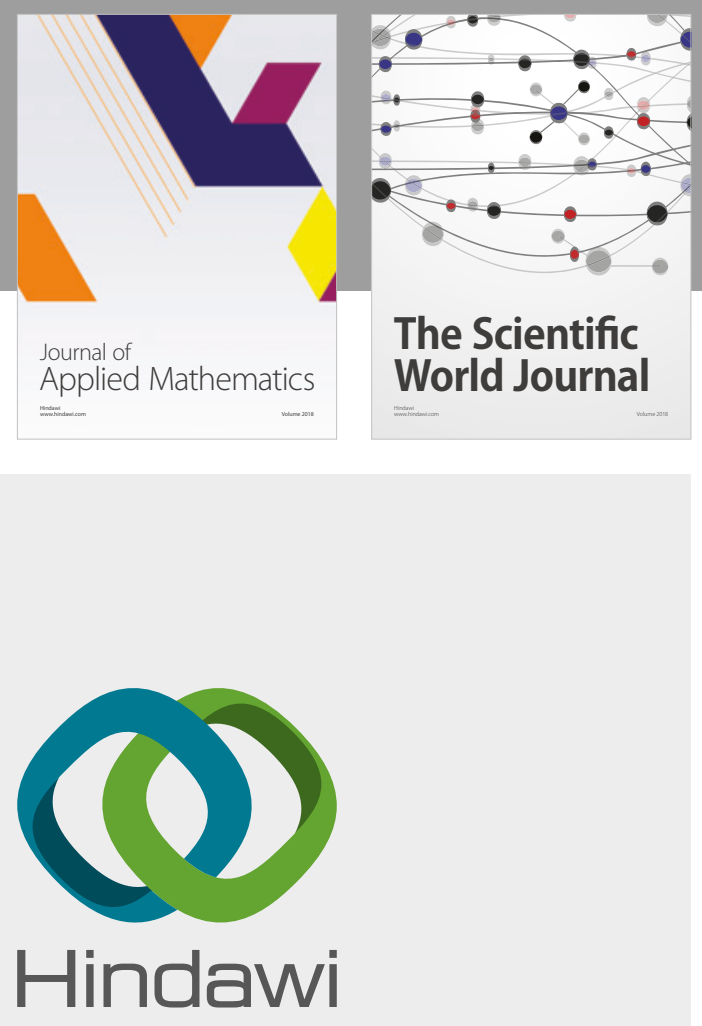

Submit your manuscripts at

www.hindawi.com

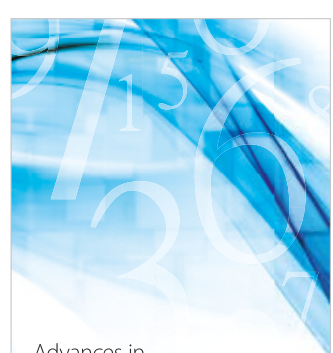

Advances in
Numerical Analysis
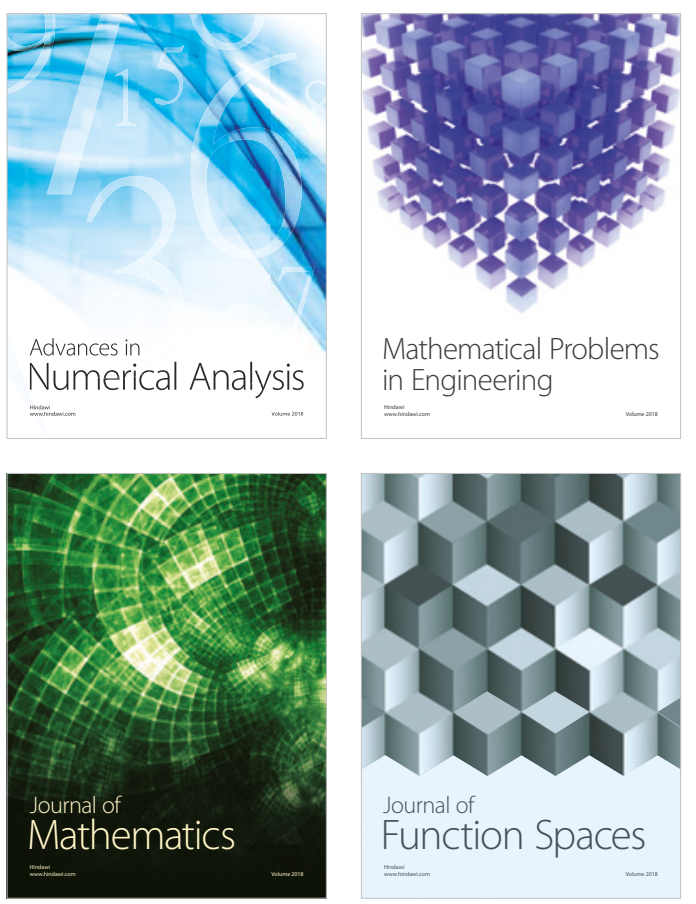

Mathematical Problems in Engineering

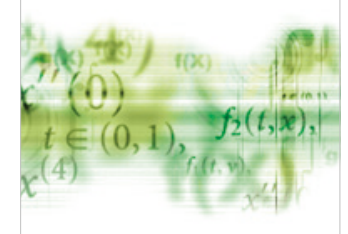

International Journal of

Differential Equations

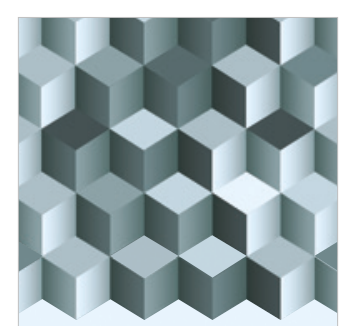

Journal of

Function Spaces
The Scientific

World Journal

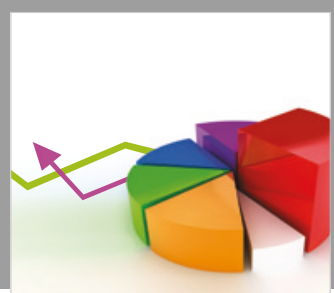

Journal of

Probability and Statistics
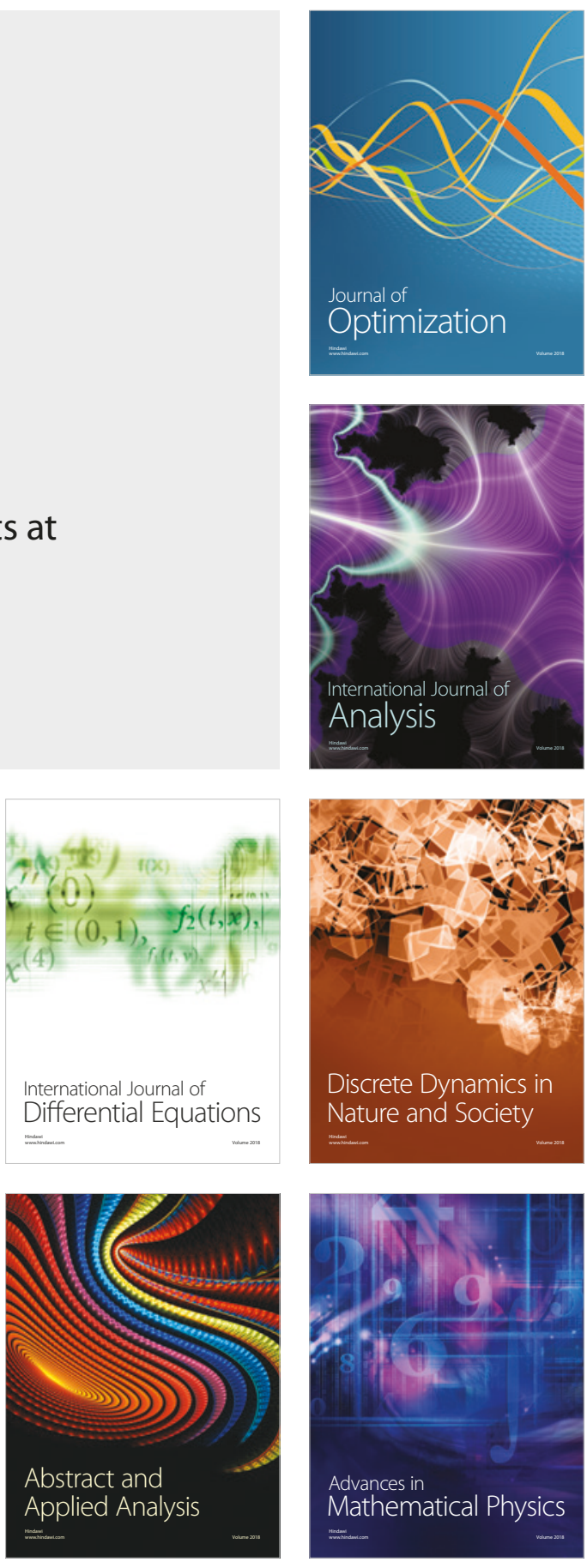